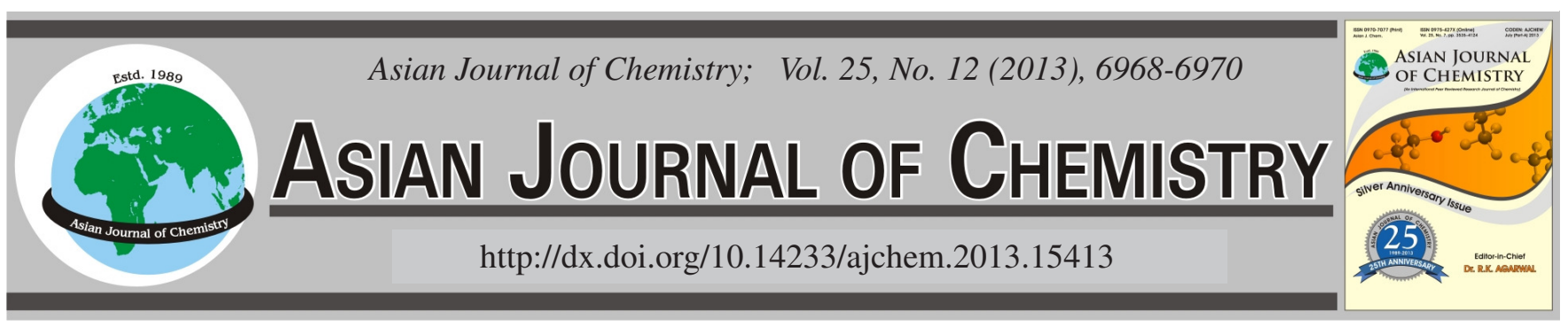

\title{
A Highly Atom Economic, Chemo-, Regio- and Stereoselective Synthesis and Crystal Structure of Novel Spiro-Cyclopentanone
}

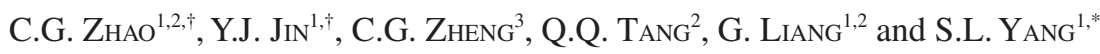

${ }^{1}$ Institute of Biotechnology, Nanjing University of Science and Technology, Nanjing 210094, P.R. China

${ }^{2}$ School of Pharmacy, Wenzhou Medical College, Wenzhou 325035, P.R. China

${ }^{3}$ Department of Coloprectology, The Second Affiliated Hospital, Wenzhou Medical College, Wenzhou 325035, P.R. China

*Corresponding author: E-mail: shulin_yang@126.com

$\dagger$ These authors contributed equally to this work.

(Received: 2 March 2013;

Accepted: 7 June 2013)

AJC-13612

The 1,3-dipolar cycloaddition of azomethine ylides derived from acenaphthenequinone and $\alpha$-amino acid (sarcosine) to a series of 2,5bis(fluorobenzylidene) cyclopentanones afforded novel spiro-cyclopentanone-pyrrolizines chemo-, regio- and stereoselectively in quantitative yields (95-96\%). The crystal structure of one compound containing bis(2,6-difluorobenzyl) (2b) is described. The cyclopentane rings in bis(2,6-difluorobenzyl) (2b) have an envelope conformation.

Key Words: 1,3-Dipolar cycloaddition, Atom economic, Spiro-cyclopentanone-pyrrolizines, X-ray crystallography.

\section{INTRODUCTION}

Spiro compounds and nitrogen heterocycles such as pyridines, pyrroles and pyrrolizines display good biological properties. The synthesis of spiro compounds has drawn considerable attention of chemists, in view of their very good biological activity ${ }^{1-4}$. In particular, 1,3-dipolar cycloaddition of nonstabilized azomethine ylides generated (Scheme-I) in situ from isatin or acenaphthenequinone and $\alpha$-amino acids to the olefinic dipolarophiles having an exocyclic bond provides a facile route for the construction of many spiroheterocycles viz. pyrrolidines and pyrrolizines, which are prevalent in a variety of biologically active compounds and find utility in the treatment of diseases such as cancer and viral infections ${ }^{5,6}$. 1,3-Dipolar cycloaddition of azomethine ylides to alkenes affords pyrrolidines with good selectivities ${ }^{7,8}$. Recently, we have reported an atom economic synthesis and evaluation of antioxidant activity of spiro pyrrolidines derivatives $^{9}$. The biological importance of spiro-pyrrolidines and our ongoing effort to discover novel anticancer lead candidates, led us to synthesize novel spiro heterocycles via 1,3-dipoar cycloaddition of azomethine ylides to a series of 2,5bis(fluorobenzylidene)cyclopentanone. We present the preliminary results on the synthesis and the structure of the first representative series of this family.

\section{EXPERIMENTAL}

All reagents were obtained from commercial sources and used directly without further purification. Melting points were

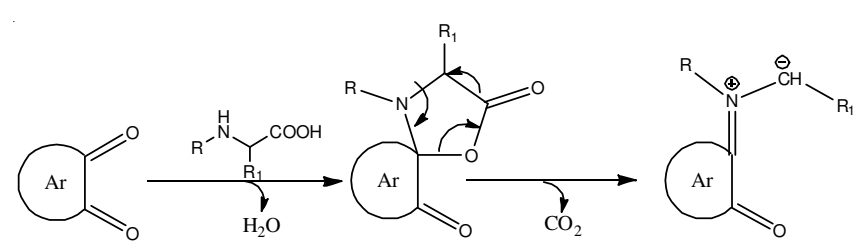

Scheme-I: Mechanism of azomethine ylide formation

determined on a Fisher-Johns melting apparatus and uncorrected. ${ }^{1} \mathrm{H}$ NMR spectra were recorded on a Bruker AVANCE 600 spectrometer. The chemical shifts were presented in terms of parts per million with TMS as the internal reference. Electronspray ionization mass spectra in positive mode (ESI-MS) data were recorded on a Bruker Esquire $3000^{+}$spectrometer.

In the present investigation, the 1,3-dipolar cycloaddition of an azomethine ylide generated in situ from acenaphthenequinone and $\alpha$-amino acids [sarcosine] to $\mathbf{1}$ afforded novel 1-methyl-4-arylpyrrolo(spiro-[2.2"]acenaphthene-1"-one)spiro[3.2']-5'-arylmethylidenecyclohexanones 2 in excellent yields $(>90.0 \%)$. Briefly, a mixture of 2,6-bis[(E)-arylmethylidene]cyclohexanone $\mathbf{1}(1 \mathrm{mmol})^{10,11}$, acenaphthenequinone $(0.182 \mathrm{~g}, 1 \mathrm{mmol})$ and sarcosine $(0.089 \mathrm{~g}, 1 \mathrm{mmol})$ was dissolved in methanol $(10 \mathrm{~mL})$ and refluxed for $0.5 \mathrm{~h}$. After completion of the reaction as evident from TLC, the mixture was cooled to room temperature and poured into water $(50 \mathrm{~mL})$. The precipitated solid was filtered and washed with water to obtain pure compound $\mathbf{2}$ as yellow solid (Scheme-II).

1-Methyl-4-(2-fluorophenyl)pyrrolo(spiro-[2.2"]acenaphthene-1"-one)-spiro[3.2']-5'-(2-fluorophenyl)- 


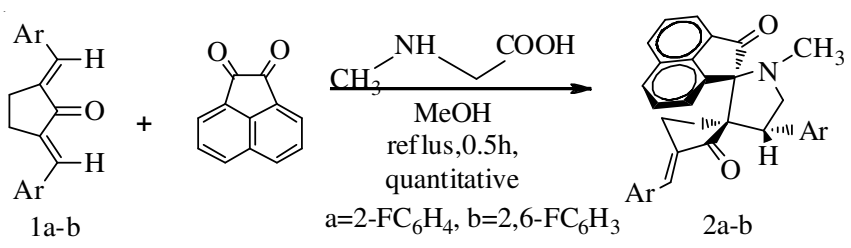

Scheme-II: Synthesis of tri-spiro cyclopentanone $\mathbf{2}$

methylidenecyclopentanone $(\mathbf{2 a})^{\mathbf{1 2}} \mathbf{:} 92.60 \%$ yield, m.p. 93.2$95.0{ }^{\circ} \mathrm{C}$. ESI-MS m/z: $506.3(\mathrm{M}+1)^{+}$calcd. for $\mathrm{C}_{33} \mathrm{H}_{25} \mathrm{NO}_{2} \mathrm{~F}_{2}$ : 505.19.

1-Methyl-4-(2,6-difluorophenyl)pyrrolo(spiro-[2.2"]acenaphthene-1"-one)-spiro[3.2']-5'-(2,6-difluoro-phenyl)methylidenecyclopentanone (2b): $95.30 \%$ yield, m.p. 131.2$132.8^{\circ} \mathrm{C} .{ }^{1} \mathrm{H}$ NMR $\left(\mathrm{CDCl}_{3}\right) \delta: 1.340\left(2 \mathrm{H}, \mathrm{m}, 4-\mathrm{CH}_{2}\right) ; 1.912$, $2.076\left(2 \mathrm{H}, \mathrm{m}, 3-\mathrm{CH}_{2}\right) ; 2.253\left(3 \mathrm{H}, \mathrm{s}, \mathrm{N}-\mathrm{CH}_{3}\right) ; 3.604,4.089$ $\left(2 \mathrm{H}, \mathrm{m}, 7-\mathrm{CH}_{2}\right) ; 4.765(1 \mathrm{H}, \mathrm{m}, 6-\mathrm{CH}) ; 7.523(1 \mathrm{H}, \mathrm{s}, \mathrm{Ar}-\mathrm{CH}=)$; 6.790-8.121 (12H, m, Ar-H). ESI-MS m/z: $542.3(\mathrm{M}+1)^{+}$calcd. for $\mathrm{C}_{33} \mathrm{H}_{23} \mathrm{NO}_{2} \mathrm{~F}_{4}: 541.17$.

$\mathrm{X}$-ray structure determination: Crystals suitable for $\mathrm{X}$-ray diffraction were obtained by slowly evaporating a solution of the solid in mixed solvent at room temperature for 2 days. Single crystals were selected and mounted on the top of glass fibres in a random orientation. X-ray singlecrystal diffraction measurement was carried out at 293(2) K on a Bruker Smart CCD area diffractometer equipped with a graphite-monochromatic $\operatorname{MoK}_{\alpha}$ radiation $(\lambda=0.71073 \AA)$ for data collection. The unit cell dimensions were obtained with the least-squares refinements and the structures were solved by direct methods with SHELXS-97 ${ }^{13}$. The final refinement was performed by full-matrix leastsquares techniques with anisotropic thermal parameters for the non-hydrogen atoms on F2 (SHELXL-97) ${ }^{13}$. All the hydrogen atoms were placed in the calculated positions and constrained to ride on their parent atoms. The important crystal data were as follows: $\mathrm{C}_{33} \mathrm{H}_{23} \mathrm{NO}_{2} \mathrm{~F}_{4}, \mathrm{~F}(000)=560$, Triclinic, $\mathrm{D}(\mathrm{cal})=.1.368 \mathrm{mg} / \mathrm{m}^{3}$, space group $\mathrm{P}_{\overline{1}}, \mathrm{a}=10.0143(9) \AA, \mathrm{b}=10.8109(10) \AA, \mathrm{c}=$ 14.0032(13) $\AA ; \alpha=112.659(2)^{\circ}, \beta=107.0090(10)^{\circ}, \gamma=$ 92.971 $(2)^{\circ} ; \mathrm{Z}=2, \mathrm{~T}=293(2) \mathrm{K}, 1.68<\theta<25.50^{\circ} ; \mathrm{R}$ (int) $=$ $0.0292, \mathrm{R} 1=0.0596, \mathrm{wR} 2=0.1681[\mathrm{I}>2 \sigma(\mathrm{I})]$.

\section{RESULTS AND DISCUSSION}

All the reactions were effected by heating an equimolar mixture of the reactants to reflux in methanol on a water-bath for $0.5 \mathrm{~h}$. After completion of the reactions (TLC), the reaction mixtures were poured into icewater, the resulting solid filtered and washed with water to afford pure compound $\mathbf{2}$ as yellow solids. No further purification was required. The only byproduct of these cycloadditions are water and carbon dioxide, the atom economy of these cycloadditions is high $(>90 \%)$. The quantitative yield in conjunction with high atom economy renders this protocol efficient and green.

All the cycloadditions proceed (i) regioselectively, as the electron rich carbon of the dipole adds to the $\beta$-carbon of the $\alpha, \beta$-unsaturated moiety of compound $\mathbf{1}$, (ii) chemoselectively, as the cycloaddition occurs on only one $\mathrm{C}=\mathrm{C}$ bond of compound 1 furnishing exclusively the mono spiro-cycloadducts 2 , ascribable to the steric hindrance exerted by the cycloadducts for the second cycloaddition, (iii) stereoselectively, as only one diastereomer is obtained exclusively in quantitative yields, although more than one stereocenter is present in these cycloadducts 2 .

The complete stereochemical information of $\mathbf{2} \mathbf{b}$ was obtained from an X-ray crystallographic study of a single crystal of $\mathbf{2 b}$ (Fig. 1). The bond lengths and bond angles in the compound $\mathbf{2 b}$, are comparable to similar structures determined previously ${ }^{14}$. This suggests that the two carbonyls linked to C-5 and C-8 of 2 are in trans relationship.

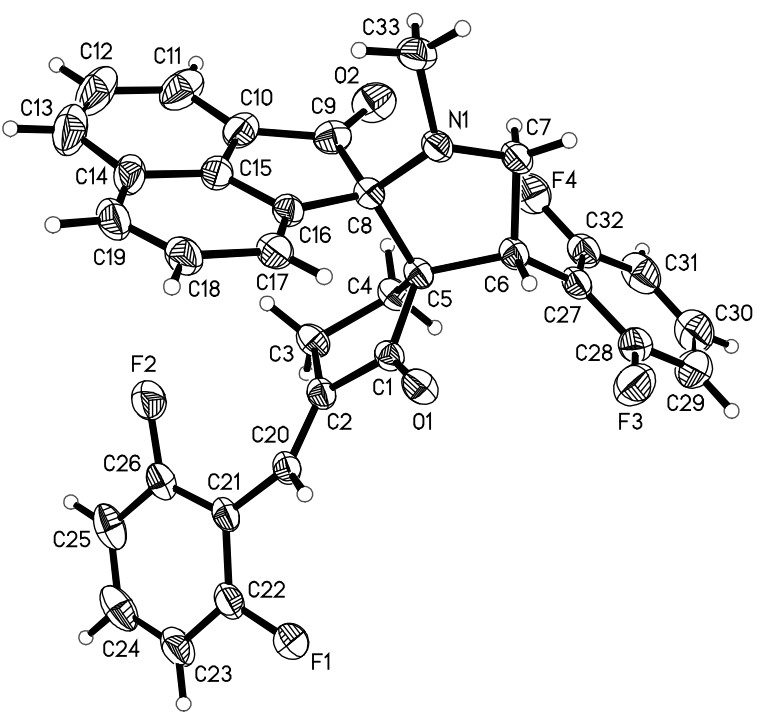

Fig. 1. Molecular structure of compound $\mathbf{2 b}$

This stereoselectivity can be understood by the fact that the corresponding transition state (A) would require less free energy of activation than the transition state (B) leading to 2' as the latter would result in electrostatic repulsion between the cis carbonyls increasing the free energy of activation (Scheme-III).
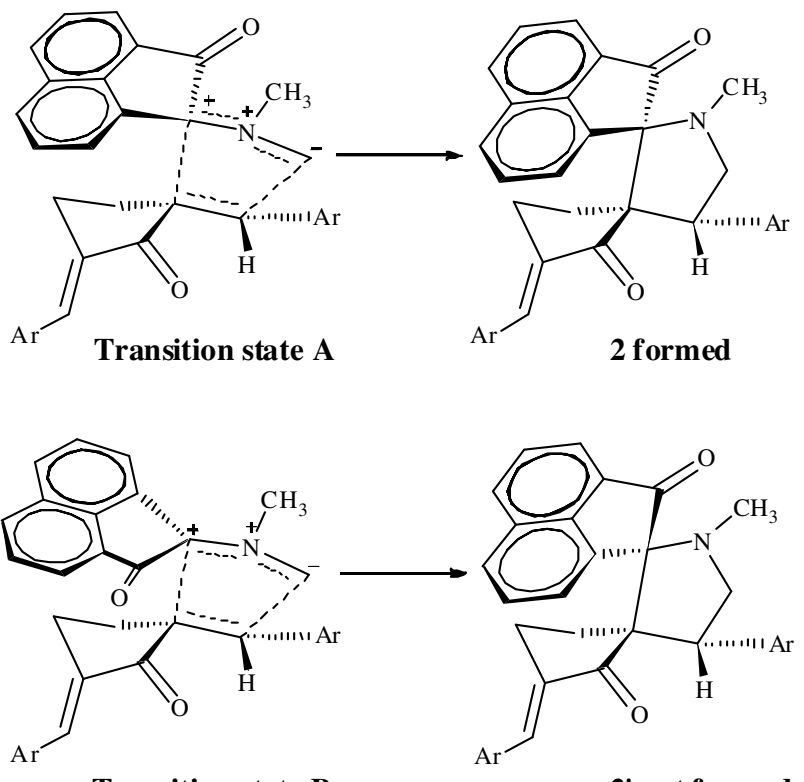

Transition state $B$

$2 '$ not f ormed

Scheme-III: Stereochemistry of cycloadducts differing in their relative configurations at C-5 and C-8 
$\mathrm{X}$-ray crystallographic analysis indicates the pyrrolidine ring (N1/C7/C6/C5/C8) adopts an envelope conformation. The sum of the bond angles around N1 atom (337.61) indicates $s p^{3}$ hybridization. The acenapthene unit is planar with a dihedral angle between the two benzene rings of $4.51(13)^{\circ}$; the dihedral angles between the benzene rings (C10-C15) and (C14 $-\mathrm{C} 19)$ and the five-membered ring are $2.44(14)^{\circ}$ and $4.41(12)^{\circ}$, respectively. The two phenyl rings (C21-C26 and C27-C32) are almost perpendicular to each other, making a dihedral angle of $89.84(13)^{\circ}$. The crystallographic data of $\mathbf{2} \mathbf{b}$ is helpful in studying the spiro-cyclopentanone-pyrrolizines.

Crystallographic data (excluding structure factors) for $\mathbf{2 b}$ have been deposited with the Cambridge Crystallographic Data Centre as supplementary publication number CCDC 793872. Copies of the data can be obtained, free of charge, on application to CCDC, 12 Union Road, Cambridge CB2 1EZ, UK [fax: +44 1223336033 or e-mail: deposit@ccdc.cam.ac.uk].

\section{Conclusion}

A facile highly atom economic synthesis of novel spiro compounds has been achieved via 1,3-dipolar cycloaddition of azomethine ylides to 2,6-bis $[(E)$-arylmethylidene $]$ cyclohexanone. Synthesis of a large number of compounds of similar structure, their screening for biological activities and investigation of structure-activity relationships are envisaged in our research group.

\section{ACKNOWLEDGEMENTS}

This work was supported by the Zhejiang Provincial Natural Science Foundation of China (grant No. LY12H16003
\& Y4110197) and Project of Wenzhou Science \& Technology Bureau (Y20100273). The X-ray crystallographic facility at the Shanghai Institute of Organic Chemistry, Chinese Academy of Sciences is gratefully acknowledged.

\section{REFERENCES}

1. K. Pluta, B. Morak-Mlodawska and M. Jelen, Eur. J. Med. Chem., 46, 3179 (2011).

2. M. Rani, R. Ramachandran and S. Kabilan, Bioorg. Med. Chem. Lett., 20, 6637 (2010).

3. F.Y. Zhang, C.L. Wu, C. Zhang and H.M. Liu, Chin. Chem. Lett., 21, 798 (2010).

4. H.T. Xi, T.T. Yi and X.Q. Sun, Chin. Chem. Lett., 21, 633 (2010).

5. R.R. Kumar, S. Perumal, P. Senthilkumar, P. Yogeeswari and D. Sriram, J. Med. Chem., 51, 5731 (2008).

6. A.S. Girgis, Eur. J. Med. Chem., 44, 91 (2009).

7. R.R. Kumar, B. Loganayaki and S. Perumal, Synth. Commun., 39, 3197 (2009).

8. K.S.L. Huang, E.H. Lee, M.M. Olmstead and M.J. Kurth, J. Org. Chem., 65, 499 (2000)

9. J.Z. Wu, W.L. Li, L.Z. Chen, S.H. Chu, C.G. Zhao, T. Wei, S.L. Yang and X.K. Li, Chin. J. Org. Chem., 32, 2141 (2012).

10. C.G. Zhao, X.Y. Chen, J. Hu, L. Zhang, Y.J. Zhao, S.L. Yang and G. Liang, Chin. J. Struct. Chem., 31, 491 (2012).

11. C.G. Zhao, Y.P. Cai, X.Z. He, J.L. Li, L. Zhang, J.Z. Wu, Y.J. Zhao, S.L. Yang, X.K. Li, W.L. Li and G. Liang, Eur. J. Med. Chem., 45, 5773 (2010).

12. G.Z. Chen, X.Q. Shen, X.X. Wu, Y. Wang and X.K. Li, Acta Cryst., E69, o249 (2012).

13. G.M. Sheldrick, Acta Cryst., A64, 112 (2008).

14. R.R. Kumar, S. Perumal, S.C. Manju, P. Bhatt, P. Yogeeswari and D. Sriram, Bioorg. Med. Chem. Lett., 19, 3461 (2009). 